\title{
Borderline Over Tümörlü 53 Olgunun Retrospektif Analizi
}

\author{
Evrim Bostancl ${ }^{1}$, Selçuk Ayas ${ }^{1}$, Ayşen Boza ${ }^{1}$, Ayşe Gürbüz1 ${ }^{1}$ Ateş Karateke ${ }^{1}$ \\ 'Zeynep Kamil Eğitim ve Araştırma Hastanesi, Kadın Hastalıkları ve Doğum Kliniği, Istanbul
}

\begin{abstract}
ÖZET
Borderline over tümörlü 53 olgunun retrospektif analizi

Amaç: Borderline over tümörü tanısı alan 53 olgunun klinik özelliklerinin, uygulanan tedavi yöntemlerinin, rekürrens ve sağkalım oranlarının belirlenmesidir.

Gereç ve Yöntem: Bu çalışmaya 2001-2011 tarihleri arasında Zeynep Kamil Kadın ve Çocuk Hastalıkları Hastanesi'nde jinekoloji kliniklerinde borderline over tümörü tanısı alan 53 olgu dahil edildi. Retrospektif olarak sosyodemografik veriler, hastalığın tanı ve tedavi süreçlerinde uygulanan yöntemler, fertilite arzusu, hastalığın progresyonu, sağkalım süreleri, rekürrens durumları değerlendirildi.

Bulgular: Ortalama yaş $45.4 \pm 15.5$ olarak hesaplandı. Olguların \%56.6'sı postmenopozal, \%43.4'ü premenopozal dönemde tanı aldı. Histolojilerin \%67.9'u seröz, \%26.4'ü müsinöz ve \%5.7'si mixt tip olarak saptandı. Olguların \%62.3'ünde kanser antijen 125 (CA-125) değeri referans aralığının ( $\geq 35 \mathrm{IU} / \mathrm{ml}$ ) üstünde bulundu. Bir olguya total abdominal histerektomi (TAH) ve bilateral salpingooferektomi (BSO), 7 olguya (\%13.2) unilateral salpingooferektomi (USO)+ diğer overden biyopsi, 14 olguya (\%26.4) USO+evreleme ve 31 olguya (\%58.5) TAH+BSO+omentektomi+bilateral pelvik paraaortik lenf nodu disseksiyonu (BPPLND) yapıldı. Kırkdokuz olgu (\%92.45) evre 1'de tanı aldı. Olguların \%39.6'sına ( $\mathrm{n}=21$ ) fertilite koruyucu cerrahi, bu olguların beşine 1 yıl içinde tamamlayıcı cerrahi uygulandı. Geriye kalan 16 olgunun beşi operasyon sonrası gebe kalırken, 1 olgu ektopik gebelik geçirdi. Olguların hiçbirinde nüks saptanmadı.

Sonuç: Borderline tümörler çok iyi prognozludur. Konservatif cerrahi reprödüktif çağda ve fertilitesinin korunmasını isteyen hastalar için değerlendirilebilir fakat hastalar nüks açısından bilgilendirilmelidir. Bizim borderline over tümörleri ile ilgili deneyimlerimiz literatür ile uyumludur.
\end{abstract}

Anahtar kelimeler: Borderline over tümörü, fertilite koruyucu cerrahi, sağkalım

\section{ABSTRACT}

Retrospective analysis of 53 cases with borderline ovarian tumors

objective: To determine of 53 cases with borderline ovarian tumors according to clinical features, treatment methods, recurrence and survival rates.

Material and Methods: Fifty-three patients with borderline ovarian tumors operated in Zeynep Kamil Hospital between 2001-2011 are included. Demographic and clinical findings, surgical methods, wish for the preservation of fertility, recurrences and survivals were evaluated.

Results: Average age of patients were $45.4 \pm 15.5$. Time at diagnosis $56.6 \%$ of the patients were in postmenopausal, $43.4 \%$ of patients were in premenopausal period. \%67.9 of the patients had serous, $26.4 \%$ of them had musinous histologic type and $5.7 \%$ of them had mixt type. Tumor markers were elevated $(\geq 35 \mathrm{IU} / \mathrm{ml})$ in $\% 62,3$ of the patients before the surgery. One of the patients were treated with total abdominal hysterectomy (TAH) and bilateral salpingo-oophorectomy (BSO), 7 of the patients (13.2\%) were treated with unilateral salpingoophorectomy (USO) and biopsy from other ovary, 14 of the patients (26.4\%) were treated with USO+bilateral pelvic and paraaortic lymphadenectomy (BPPLND) and omentectomy, 31 of patients (58.5\%) were treated with TAH+BSO+BPPLND+omentectomy. Forty-nine of the patients $(92.45 \%)$ were stage I. $39.6 \%(n=21)$ of the patients were treated with fertility sparing surgery but five of them were reoperated in 1 year. Totally $30.2 \%(n=16)$ of the patients were treated with fertility sparing surgery. We have had 5 babies and 1 ectopic pregnancy after fertility sparing surgery. Furthermore we have not seen any recurrence during our follows-up.

Conclusion: Borderline ovarian tumors have perfect prognosis. Conservative treatment of borderline ovarian tumors should be consider in patients with fertilty desire and at reproductive age but patients should be warned for recurrences rates. Our experiences are coherent with literature

Key words: Borderline ovarian tumor, fertility sparing surgery, survival

Bakırköy Tıp Dergisi 2014;10:27-32

Yazışma adresi / Address reprint requests to: Evrim Bostancı

Zeynep Kamil EAH, Kadın Hastalıkları ve Doğum Kliniği, Üsküdar, ìstanbul

Telefon / Phone: +90-505-617-9623

Elektronik posta adresi / E-mail address: evrimbostanc6666@gmail.com

Geliş tarihi / Date of receipt: 25 Eylül 2013 / September 25, 2013

Kabul tarihi / Date of acceptance: 27 Kasım 2013 / November 27, 2013 


\section{Giriş}

$\mathrm{B}$ orderline over tümörleri (BOT) ilk olarak 1929 yılında 'semi malign tümör' olarak adlandırılmış, 1971 yılında ise International Federation of Obstetric Gynecology (FIGO) tarafından over tümörlerinin ayrı bir kategorisi olarak sınıflandırılmıştır $(1,2)$. BOT epitelyal over tümörlerinin yaklaşık \%15-20'sini oluşturmakta ve en sık 30-50 yaşlar arasında görülmektedir (3). BOT için önerilen tedavi; TAH, BSO, omentektomi, peritoneal biyopsi, peritoneal yıkama sıvısı örneklemesi, bütün makroskopik lezyonların çıkarılması ve müsinöz tümörler için appendektomiyi içerir (4). Rutin pelvik ve paraaortik lenf nodu disseksiyonu tartışmalıdır, invaziv lezyon yokluğunda gerekli olmayabilir (5). Over kanserine göre daha genç yaşlarda tanı konulduğundan, BOT’lerinde fertilite koruyucu cerrahinin önemi artmaktadır. Fertilite koruyucu cerrahinin nüks riskini arttırdığı ancak sağkalımı etkilemediği saptanmıştır $(4,6,7)$.

Bu çalışmanın amacl; hastanemizde BOT tanısı alan hastalarda uygulanan tedavi yaklaşımını ve sonuçlarını incelemektedir.

\section{GEREÇ VE YÖNTEM}

Bu retrospektif çalışmaya, hastanemiz jinekoloji servisinde 2001-2011 yılları arasında opere edilen 53 BOT olgusu dahil edildi. Çalışma hastane etik kurulu tarafından onaylandı. Veriler olguların jinekoloji servisi takip dosyalarından ve hastalar telefonla aranarak elde edildi. Bu olgular; tanı anındaki yaşı, başvuru şikayeti, menopozal durum, fertilite arzusu, infertilite tedavisi alıp almadığı, tümör evresi, tümör çapı, cerrahi tedavi şekli, adjuvan tedavi uygulanıp uygulanmadığı, takip protokolü, sağ kalım, rekürrens ve ölüm açısından değerlendirildi. Olguların preoperatif değerlendirilmesinde transvajinal ultrasonografi (USG), pelvik muayene, tümör markerleri, servikal smear, endometrial örnekleme ve gerek görülen olgularda pelvik magnetik rezonans (MR) görüntüleme yöntemi kullanıldı. Cerrahi tedavi; olguların fertilite arzususunun yanı sıra frozen inceleme sonucu ve operasyondaki tümör yaygınlığına göre modifiye edildi. Fertilite arzusu olmayan olgulara TAH+BSO, BPPLND (+/-), omentektomi (+/-), batın yıkama sıvısı örneklemesi (BYSÖ) (+/-), appendektomi (+/-) yapilırken, fertilite arzusu olan hastalara USO, BPPLND (+/-), omentektomi (+/-), BYSÖ (+/-) yapıld. Eksplorasyonda tümöral açıdan şüpheli görülen alanlardan biyopsi alındı ve makroskobik olarak görülen tümöral yayılımlar rezeke edildi. Operasyondan elde edilen materyaller hastanemiz patoloji bölümü ekibi tarafından değerlendirildi. Olgular FIGO (International Federation of Gynecology and Obstetrics) 2009 sistemine göre evrelendirildi (8). Hastalar postoperatif ilk yılda her 3 ayda bir, sonraki beş yılda 4 ayda bir, daha sonraki beş yılda 6 ayda bir rutin kontrollere çağrıldı. Kontroller sırasında her vizitte kapsamlı bir fizik muayene, jinekolojik muayene, pelvik/transvajinal USG ve serum CA-125 düzeyi, hemogram istendi. Her sene bilgisayarlı tomografi (BT), akciğer grafisi, glukoz, kreatinin, alanin aminotransferaz, aspartat aminotransferaz, ürik asit düzeyleri istendi.

Verilerin değerlendirilmesinde, istatistiksel analizler için SPSS (Statistical Package for Social Sciences for Windows 15.0) programı kullanıldı. Verilerin değerlendirilmesinde tanımlayıcı istatistiksel metotların (ortalama

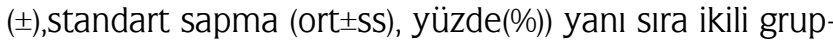
ların karşılaştırmasında Mann-Whitney-U testi, nitel verilerin karşılaştırmalarında ki-kare testi kullanıldı. $p<0.05$ değeri istatistiksel olarak anlamlı kabul edildi.

\section{BULGULAR}

Ortalama yaş $45.4 \pm 15.5$ idi. Olguların 43.4 'ü 40 yaş altında olup; opere olan en genç hasta 22 yaşında, en yaşlı olgu 84 yaşında idi. Fertilite koruyucu cerrahi geçiren olguların yaş ortalaması $27.9 \pm 12.2$ idi. Olguların \%56.6'sı postmenopozal, \%43.4'ü premenopozal idi. Olguların \%28.3'ünün vücut kitle indeksi $30 \mathrm{~kg} / \mathrm{m}^{2}$ 'nin üzerinde olup, seröz ve musinöz patolojiler arasında istatiksel fark anlamlıdır $(\mathrm{p}=0.016$ ). Olguların \%20.8'i sigara kullanmaktaydı. Sigara kullanımının seröz ve müsinöz patolojilere göre dağılımı istatiksel olarak anlamlıdır $(p=0.044)$. Altı olgunun 1. derece akrabasında kanser öyküsü mevcuttu. Ailede kanser öyküsü olanların hepsinin patolojisi seröz BOT olarak saptandı. iki olguda infertilite hikayesi mevcuttu. Olgulardan biri 6 siklus klomifen sitrat ve 3 siklus gonadotropin kullanmış olup diğerinin tedavi almadığı saptandı.

Yirmi bir olguda USG'de papiller uzanım gösteren, semisolid, septalı kitleler izlendi. Bir olguda ise asit bulgusu pozitifti. CA-125 düzeyi maksimum $1637 \mathrm{IU} / \mathrm{ml}$, minimum 4IU/ml olarak ölçüldü. Otuz üç olguda (\%62.3) CA-125 değeri referans aralığının ( $\geq 35 \mathrm{IU} / \mathrm{ml}$ ) üstünde saptandı. Seröz ve müsinöz BOT arasında CA-125 yüksekliği (>35IU/ml ) açısından istatiksel bir fark bulunmamakla beraber seröz BOT'de CA-125 düzeyleri müsinöz tümörle- 
Tablo 1: Olguların tanı anındaki yaş ortalaması, menapoz durumuna göre dağılımı, sigara kullanımı ve obezitenin histolojik tiplere göre dağılımı.

\begin{tabular}{|c|c|c|c|}
\hline & $\mathrm{n}$ & $\%$ & p değeri \\
\hline Yaş ort. (yll \pm SD) & $45.4 \pm 15.5$ & & \\
\hline Menapoz & 30 & 56.6 & \\
\hline Obezite $(\mathrm{VKI}>30)$ & 15 & 28.3 & \\
\hline seröz & 8 & & $0.016^{*}$ \\
\hline müsinöz & 4 & & \\
\hline $\operatorname{mixt}$ & 3 & & \\
\hline Sigara kullanımı & 11 & 20.8 & \\
\hline seröz & 5 & & $0,044^{*}$ \\
\hline müsinöz & 6 & & \\
\hline $\operatorname{mixt}$ & 0 & & \\
\hline Ailede kanser öyküsü & 6 & 11.3 & \\
\hline
\end{tabular}

Ki-Kare Test * $\mathrm{p}<0.05$

Tablo 2: Olguların CA-125 değerine, histolojik tiplerine, mikroinvazyon varlığına, yapılan operasyonlara göre dağlımı

\begin{tabular}{lcc}
\hline & $\mathbf{n}$ & $\%$ \\
\hline CA-125 & 33 & 20 \\
$\quad 335 \mathrm{IU} / \mathrm{ml}$ & 62.3 & 37.7 \\
$\quad<35 \mathrm{IU} / \mathrm{ml}$ & 43 & 96.2 \\
Frozen doğruluk oranı & & \\
Histoloji & 36 & 67.9 \\
$\quad$ seröz & 14 & 26.4 \\
$\quad$ müsinöz & 3 & 5.7 \\
$\quad$ miks tip & 4 & 7.5 \\
mikroinvazyon & & \\
Operasyon & 7 & 13.2 \\
$\quad$ USO + contralateral over biyopsi & 14 & 26.4 \\
$\quad$ USO + evreleme & 1 & 1.9 \\
$\quad$ TAH + BSO & 31 & 58.9 \\
$\quad$ TAH + BSO + evreleme & 22 & 41.6 \\
Appendektomi & 45 & 84.9 \\
Lenfadenektomi & 18 & \\
pelvik & 27 & \\
pelvik + paraaortik & & \\
&
\end{tabular}

re göre daha yüksek saptandı ( $240 \pm 358$ vs $49 \pm 33$ ). Frozen kesit yapılma oranı \%84.9 $(\mathrm{n}=45)$, frozen doğruluk oranı \%96.2 olarak hesaplandı.

Histolojik olarak olguların \%67.9'u seröz, \%26.4'ü müsinöz ve \%5.7'si mikst tip olarak değerlendirildi. Dört olgu histolojik olarak mikroinvaziv BOT olarak saptandı. Makroskopik incelemede ortalama tümör çapı $11.54 \pm 8.42 \mathrm{~cm}$ olarak hesaplandı. Seröz ve musinöz BOT'leri ortalama tümör çapları açısından karşılaştırıldığında istatiksel olarak anlamlı bir fark saptanmadı.

Dört olguya laparoskopi yapıldı ancak 2 olguda frozen sonucunda laparotomiye geçildi. Diğer 49 olguya laparotomi plandı. Bir olguya TAH ve BSO, 7 olguya (\%13.2) USO ve diğer overden biyopsi, 14 olguya (\%26.4) USO, omektektomi, BPPLND ve 31 olguya (\%58.5) TAH, BSO ve evreleme yapıldı. Frozen sonucu musinöz olan vakaların tümüne, seröz olanların ise \%25'ine appendektomi yapıldı. Evreleme yapılan olgularda ortalama diseke edilen pelvik lenf nodu sayısı $12 \pm 9$, paraaortik lenf nodu sayısı $3.2 \pm 4.4$ olarak hesaplandı. Lenfadenektomi yapılan olguların hiçbirinde lenf nodu invazyonu saptanmadı. íki olgu ikinci trimesterda (16 hafta ve 19 hafta) gebe iken opere edildi. Olgulardan birine USO+evreleme, diğerine USO+diğer overden biyopsi yapıldı. Gebelik takiplerinde problem yaşanmayan iki olgu da miadında doğum yaptı. Evreleme yapılmayan olgunun, evreleme cerrahisi postpartum 6.haftasında yapıldı.

Kırkdokuz olgu (\%92.4) evre 1, 4 olgu (\%7.6) evre 3 olarak saptandı. Kırkbeş olgu evre 1a, 4 olgu evre $1 \mathrm{~b}$ olarak tespit edildi. Yirmibir olguya (\%39.6) fertilite koruyucu cerrahi uygulandı. Bu olguların beşine fertilite isteklerinden vazgeçmeleri üzerine 1 yıl içerisinde tamamlayıcı cerrahi uygulandı. Geriye kalan 16 olgunun operasyondan sonra takip süresi ortalama 4.6 yll olarak hesapland ve nüks saptanmadı. Sağkalım oranı \%100 olarak hesaplandı. Fertilite koruyucu cerrahi yapılan olguların 5 tanesi operasyon sonrasında gebe kalırken, 1 tanesi ektopik gebelik geçirdi.

Ortalama takip süresi 6.2 yıl (min: 1 yıl, max: 12 yll) olarak hesaplandı. Olguların \%58.5'inde operasyon sonrası takip süresinin 5 yılı aştığı ve nüks izlenmediği saptandı. Dört olguda periton implantları pozitif saptandı ve kemoterapi planlandı. Sağ kalım oranı \%98.1 olarak hesaplanan çalışmada, 1 olgu sistemik hastalık nedeniyle kaybedildi.

\section{TARTIŞMA}

BOT, over kanserine göre daha genç yaşta, en sık reprodüktif çağda görülmekte bundan dolayı tedavisinde 
fertilite koruyucu cerrahinin önemi artmaktadır (3). Çalışmamızda yaş ortalaması $45.4 \pm 15.5$ olarak hesaplandı ve olguların \%43.4'ünün 40 yaşın altında olduğu görüldü. Fertilite koruyucu cerrahi geçiren olguların yaş ortalamaSI 27.9 \pm 12.2 olarak hesaplandı. Konservatif cerrahi (fertilite koruyucu cerrahi) uterus ve en azından bir overin bir parçasının korunduğu evreleme cerrahisi olarak tanımlanır (9). Çalışmamızda yirmi bir olguya fertilite koruyucu cerrahi yapıldı. Ancak 5 olgu fertilite arzusundan vazgeçmesi ve kanser korkusu nedeniyle, 1 yll içerisinde tamamlayıcı cerrahi operasyon geçirdi. Geriye kalan 16 olgu (\%30.2) çalışmamızın verilerinin tamamlandığı Ocak 2013 tarihine kadar takip edildi ve nüks izlenmedi. Literatürde nüks görülme oranı adneksektomiden sonra $\% 0$ ile $\% 20$, kistektomiden sonra $\% 12$ ile $\% 58$, radikal cerrahiden sonra \%2.5 ile \%5.7 arasında saptanmıştır. Nüks çok geç de ortaya çıkabilir, primer cerrahiden 39 yıl sonra görülen vaka bildirilmiştir $(10,11)$. Yapılan çalışmalarda multifokal lezyon ve cerrahi sınırda tümör varlığı, BOT'ünün persiste ve nüks etmesinde doğrudan etkili olduğu saptanmıştır. Bu yüzden bazı yayınlar konservatif cerrahide rezeksiyon sınırını geniş tutmanın önemini vurgulasa da Güvenal ve arkadaşları 2013 yılında yaptıkları çalışmada geniş cerrahi rezeksiyonun sağ kalımı etkilemediğini saptamışlardır $(7,12)$. Morice ve arkadaşları 2012 yılındaki çalışmalarında konservatif cerrahi yapılan BOT'lerinde invasiv karsinoma ilerleme riskinin \%2 ile \%3 arasında olduğunu yayınlamışlardır (13). Çalışmamızda olguların fertilite koruyucu cerrahi sonrası ortalama takip süresi 4.6 yıl olarak hesaplandı, nüks hiçbir olguda saptanmadı. Bir olgunun takiplerinde nüks şüphesi olması üzerine olguya tamamlayıcı cerrahi yapıldı, ancak nihai patolojide nüks bulgusu saptanmadı. BOT nedeniyle fertilite koruyucu cerrahi geçiren olguların \%50'si spontan gebe kalabilmektedir (14). Çalışmamızda fertilite koruyucu cerrahi yapılan olguların 5 tanesi operasyon sonrasında gebe kalırken, 1 tanesi ektopik gebelik geçirdi. Ancak bu olguların iki tanesi in vitro fertilizasyon (IVF) ile gebe kalabildi. Yapılan çalışmalar fertilite koruyucu cerrahinin IVF başarısını etkilemediğini göstermiştir (15).

Çalışmamızda dört olguda nulliparite, iki olguda ise infertilite hikâyesi mevcuttu. Olgulardan biri 6 siklus klomifen sitrat ve 3 siklus gonadotropin kullanmış, diğeri tedavi almamıştı. Literatür primer infertilite ve nulliparitenin BOT riskini arttırdığını, oral kontraseptif kullanımı, gebelik ve emzirmenin riski azaltığını ayrıca BOT tanısı alan olgularda infertilite oranının \%10 ile \%35 arasında değiştiğini saptamıştır (12). Burger ve arkadaşları yaptığı çalışmada ovulasyon indüksiyonunun BOT riskini arttırdığı ve bu riskin 15 yıl devam ettiğini göstermişlerdir (16).

Vakalarımızın \%67.9'unun seröz, \%26.4'ünün müsinöz ve \%5.7'sinin mikst tip olduğu görüldü. Literatürde de BOT’lerinin \%43-53'ünü seröz, \%42.5-52'sini müsinöz geri kalan \%4-5'ini de endometrioid, berrak hücreli, mikst ve transizyonel histoloji tipleri oluşturmaktadır (9). Serimizde frozen doğruluk oranı \%96.2 olarak tespit edildi. Gorisek ve arkadaşları 2009 yılında yaptıkları çalışmada; frozen doğruluk oranının \%85 olarak saptamışlardır (17). Yüksek frozen tutarlılığını hastanemizin jinekopatolojide spesifik olmasıyla açıklanabilir.

Çalışmamızda dört olguda mikroinvazyon saptandı. Üçünün mikst tip, birinin seröz BOT olduğu görüldü. íki olguda mikroinvazyona mikropapiller paternde eşlik etmekteydi. Bu olgularda operasyondan sonra geçen ortalama takip süresi 2.5 yıl olarak hesaplandı, nüks izlenmedi, sağ kalım \%100 olarak saptandı. Yapılan çalışmalar mikropapiller patern içeren seröz BOT'nin daha kötü prognoza sahip olduğunu göstermiştir $(18,19)$. Ancak mikropapiller paternin prognostik değeri halen tartışmaIıdır (20). Gerçekten de Kurman ve arkadaşları mikropapiller patern varlığının prognozu etkilemediğini, ancak invaziv periton implantı ile beraberliğinin kötü prognoz göstergesi olduğunu bulmuşlardır (21). Calışmamızda iki olguda mikropapiller patern tespit edildi. Olgulardan bir tanesinde non-invaziv periton implantlarına mikroinvazyon da eşlik etmekteydi. Olguların ikisine de TAH+BSO+BPPLND+omentektomi yapıldı. Ardından 6 kür kemoterapi alan vakaların operasyon sonrası ortalama izlem süresi 2.3 yıl olarak hesaplandı. Vakalarda nüks izlenmedi, sağ kalım \%100 olarak tespit edildi.

BOT için önerilen tedavi: TAH, BSO, omentektomi, peritoneal biyopsi, peritoneal yıkama, bütün makroskopik peritoneal lezyonların çıkarılması ve müsinöz tümörler için appendektomiyi içerir (4). Bizde çalışmamızda olgulara konservatif (USO, kontralateral over biyopsi (+/-), evreleme(+/-))ve radikal (TAH + BSO, evreleme(+/-)) cerrahi planladık. Yapılan çalışmalarda ileri evre (FIGO evre 2-3) BOT'lerinde lenf nodu tutulumunun yaklaşık \%25 saptanmasına rağmen, çalışmamızdaki olgularımızın hiçbirinde lenf nodu tutulumu izlenmedi (22). Serimizdeki rezidüel hastalıklı, ileri evre ve mikroinvazyon saptanan BOT olgularına $(\mathrm{n}=9)$ platinli kemoterapi rejimleri kullanıldı. Yapılan çalışmalarda rezidüel hastalıklı BOT'lerinde Sisplatinli kemoterapi rejimleri ile yüksek yanıt izlenmiş ancak sağ 
kalımı uzatmada beklenen fayda sağlanamamıştır. Trope ve arkadaşları 2009 yılındaki yayınında; ileri evre BOT'lerinde; invaze implant varlığında bile, adjuvan kemoterapi ya da radyoterapinin kanıtlanmış bir yararının olmadığını göstermişlerdir (23). Yapılan çalışmalarda lenf nodu disseksiyonunun, ne nüksü ne de sağkalımı etkilemediği gösterilmiştir $(7,8,24)$. Ayrıca apendektominin de sağkalımı etkilemediği saptanmıştır (7).

Sağ kalım oranı \%98,1 olarak hesaplanan çalışmamızda, 1 olgu sistemik hastalık nedeniyle kaybedildi. Yapılan çalışmalarda da erken evre BOT (FIGO evre 1-2) için 5 yıllık sağ kalım oranını neredeyse \%100, ileri evreler için (FIGO evre 3-4) \%86 ile 92 arasında değiştiğini göstermiştir (9).

\section{KAYNAKLAR}

1. Taylor HCJr. Malignant and semi malignant tumors of the ovary. Surg Gynecol 1929; 48: 204-230.

2. Classification and staging of malignant tumors in the female pelvis. Acta Obstet Gynecol Scand 1971; 50: 1-7.

3. Lenhard MS, Mitterer S, Kümper C, et al. Long-term follow-up after ovarian borderline tumor: relapse and survival in a large patient cohort. Eur J Obstet Gynecol Reprod Biol 2009; 145: 189-194.

4. Uzan C, Kane A, Ret A, et al. How to follow upadvanced-stage borderline tumours? Mode of diagnosis of recurrence in a large series stage 2- 3 serous borderline tumors of ovary. Ann Oncol 2011; 22: 631-635

5. Yazbek J, Raju KS, Ben-Nagi J, Holland T, Hillaby K, Jurkovic D. Accuracy of ultrasound subjective 'pattern recognition' for the diagnosis of borderline ovarian tumors. Ultrasound Obstet Gynecol 2007; 29: 489-495.

6. Park JY, Kim DY, Kim JH, Kim YM, Kim YT, Nam JH. Surgical management of borderline ovarian tumors: the role of fertilitysparing surgery. Gynecol Oncol 2009; 113: 75-82.

7. Guvenal T, Dursun P, Hasdemir PS ve ark. Effect of surgical staging on 539 patients with borderline ovarian tumors: A Turkish Gynecologic Oncology Group study. Gynecol Oncol 2013: S00908258(13)01123-2. doi: 10.1016/j.ygyno.2013.08.038. Epub ahead of print

8. Corrigendum to "FIGO staging for uterine sarcomas". Int J Gynecol Obstetr 2009; 104:179.

9. Trillsch F, Mahner S, Ruetzel J, et al. Clinical management of borderline ovarian tumors. Expert Rev Anticancer Ther 2010; 10: 1115-1124.

10. Silva EG, Gershenson DM, Malpica A, et al. The recurrence and the overall survival rates of ovarian serous borderline neoplasms with noninvasive implants is time dependent. Am J Surg Pathol 2006; 30: 1367-1371.

11. Cadron I, Leunen K, Van Gorp T, et al. Management of borderline ovarian neoplasms. J Clin Oncol 2007; 25: 2928-2937.

12. Fauvet $\mathrm{R}$, Poncelet $\mathrm{C}$, Boccara J, et al. Fertility after conservative treatment for borderline ovarian tumors: a French multicenter study. Fertil Steril 2005; 83: 284-290.
Çalışmamızda olguların 5 tanesi laparoskopi ile opere oldu ancak 2 olguda frozen sonucuna göre evreleme cerrahisi planlanıp, laparotomiye geçildi. Olgularda kist rüptürü izlenmedi. Yapılan çalışmalarda laparoskopi, laparotomiyle karşılaştırıldığında kist rüptürü ve eksik evreleme riskinin daha çok olduğu çalışmada gösterilmiştir (\%33.9'e karşı \%12)(12,25).

Sonuç olarak; BOT'lerde konservatif cerrahi fertilite arzusu olan ve fertilitesini tamamlamamış olgularda göz önünde tutulmalı, ancak hasta nüks açısından bilgilendirilmelidir. Çalışmamızda konservatif cerrahi yaptığımız olgularda nüks izlemedik. Bizim BOT'leri ile ilgili deneyimlerimiz literatür ile uyumludur.
13. Morice P, Uzan C, Fauvet R, Gouy S, Duvillard P, Darai E. Borderline ovarian tumour: pathological diagnostic dilemma and risk factors for invasive or lethal recurrence. Lancet Oncol 2012; 13: e103-e115.

14. Gotlieb WH, Flikker S, Davidson B, et al. Borderline tumors of the ovary: fertility treatment, conservative management, and pregnancy outcome. Cancer 1998; 82: 141-146.

15. Fasouliotis SJ, Davis O, Schattman G, et al. Safety and efficacy of infertility treatment after conservative management of borderline ovarian tumors: a preliminary report. Fertil Steril 2004; 82: 568-572.

16. Burger CW, van de Swaluw A, Mooij TM, et al. Risk of borderline and invasive ovarian tumors after ovarian stimulation for in vitro fertilization in a large Dutch cohort after 15 years of follow-up. Abstracts presented for the 40th Annual Meeting of the Society of Gynecologic Oncologists February 2009 (abstract no 6). Gynecol Oncol 2009; 112 (Suppl.): S4.

17. Gorisek B, Stare MR, Krajnc I. Accuracy of intra-operative frozen section analysis of ovarian tumours. J Int Med Res 2009; 37: 11731178.

18. Longacre TA, McKenney JK, Tazelaar HD, et al. Ovarian serous tumors of low malignant potential (borderline tumors): outcomebased study of 276 patients with long-term ( $>5$-year)follow up. Am J Surg Pathol 2005; 29: 707-723.

19. Deavers MT, Gershenson DM, Tortolero-Luna G, Malpica A, Lu KH, Silva E. Micropapillary and cribriform patterns in ovarian serous tumors of low malignant potential: a study of 99 advanced stage cases. Am J Surg Pathol 2002; 26: 1129-1141.

20. Prat J. Serous tumors of the ovary (borderline tumors and carcinomas) with and without micropapillary features. Int J Gynecol Pathol 2003; 22: 25-28.

21. Kurman RJ, Seidman JD, Shih IM. Serous borderline tumours of the ovary. Histopathology 2005; 47: 310-315.

22. Leake JF, Rader JS, Woodruff JD, et al. Retroperitoneal lymphatic involvement with epithelial ovarian tumors of low malignant potential. Gynecol Oncol 1991; 42: 124-130.

23. Tropé C, Davidson B, Paulsen $T$ et al. Diagnosis and treatment of borderline ovarian neoplasms 'the state of the art'. Eur J Gynaecol Oncol 2009; 30: 471-482. 
24. Kaern J, Tropé CG, Abeler VM. A retrospective study of 370 borderline tumors of the ovary treated at the Norwegian Radium Hospital from 1970 to 1982. A review of clinicopathologic features and treatment modalities. Cancer 1993; 71: 1810-1820.
25. Vandenput I, Amant F, Vergote I. Peritoneal recurrences might be less common in advanced stage serous borderline ovarian tumors that were treated by laparotomy. Gynecol Oncol 2005; 98: 523. 